NBER WORKING PAPER SERIES

\title{
SOURCES OF BIAS AND SOLUTIONS TO BIAS IN THE CPI
}

\author{
Jerry Hausman
}

Working Paper 9298

http://www.nber.org/papers/w9298

\author{
NATIONAL BUREAU OF ECONOMIC RESEARCH \\ 1050 Massachusetts Avenue \\ Cambridge, MA 02138 \\ October 2002
}

Peter Diamond and Ariel Pakes provided useful discussions. Erwin Diewert provided many comments and has made many suggestions in my research on this topic over the years. Amy Sheridan provided research assistance. The views expressed herein are those of the authors and not necessarily those of the National Bureau of Economic Research.

(C) 2002 by Jerry Hausman. All rights reserved. Short sections of text, not to exceed two paragraphs, may be quoted without explicit permission provided that full credit, including ${ }^{C}$ notice, is given to the source. 
Sources of Bias and Solutions to Bias in the CPI

Jerry Hausman

NBER Working Paper No. 9298

October 2002

JEL No. C43, D12, D43

$\underline{\text { ABSTRACT }}$

Four sources of bias in the Consumer Prices Index (CPI) have been identified. The most discussed is substitution bias, which creates a second order bias in the CPI. Three other changes besides prices changes create first order effects on a correctly measured cost of living index (COLI). (1) Introduction of new goods creates a first order effect of "new good bias" (2) Quality changes in existing goods will lead to "quality" bias, which has first order effects (3) Shifts in shopping patterns to lower priced stores can create first order "outlet bias". I explain in this paper that a "pure price" based approach of surveying prices to estimate a COLI cannot succeed in solving the 3 problems of first order bias. Neither the BLS nor the recent report C. Schultze and C. Mackie, eds., At What Price (AWP, 2002), recognizes that to solve these problems, which have been long known, both quantity and price data are necessary. I discuss economic and econometric approaches to measuring the first order bias effects as well as the availability of scanner data that would permit implementation of the techniques. Lastly, I review recent research that demonstrates that these sources of bias are large in relation to measured inflation in the CPI.

Jerry Hausman

Department of Economics

MIT

50 Memorial Drive

Cambridge, MA 02142

and NBER

jhausman@mit.edu 


\title{
Sources of Bias and Solutions to Bias in the CPI
}

\author{
Jerry Hausman, MIT ${ }^{1}$ \\ September 30, 2002
}

\section{Introduction}

Return to the days of $19^{\text {th }}$ century London of Dickens' characters and impenetrable fogs. A social reformer decides to measure the required minimum cost for a family of four to have a "proper lifestyle". The social reformer defines the needed quantities or "basket" of goods and ventures into the fog to find the prices for the goods in questions. A year later she goes out again to measure how prices have changed to recompute her crude cost of living index (COLI). J. Lowe advocated this approach in $1823 .^{2}$

As "every schoolboy knows" (an English expression) this "constant basket" approach suffers from numerous biases and flaws. The most-discussed flaw is the failure to allow for substitution. When some prices increase the consumer will switch to cheaper goods, and vice versa. Use of a constant basket with period 1 quantities, the Laspeyres approach, will overestimate the change in the COLI, leading to "substitution bias". ${ }^{3}$ However, this substitution bias has only a second order effect on the measurement of a

\footnotetext{
${ }^{1}$ Peter Diamond and Ariel Pakes provided useful discussions. Erwin Diewert provided many comments and has made many suggestions in my research on this topic over the years. Amy Sheridan provided research assistance.

${ }^{2}$ See Diewert (1993) for an interesting early history of price index research. Dickens was 11 years old in 1823.

${ }^{3}$ Use of period 2 quantities, the Paasche approach, yields the opposite problem. Konus (1924) demonstrated that the COLI is bounded by the Paasche and Laspeyres price indices. Bowley (1899) and I. Fisher (1922) recommended using the geometric mean of the two indices which yielded the first "second order approximation" that accounts for substitution effects.
} 
correct COLI. ${ }^{4}$ Calculation of the change in the CPI accounts for the first order effect by multiplying the period 1 quantities by the change in prices.

Three other changes besides prices changes create first order effects on a correctly measured COLI. They will create first order biases in a CPI if they are ignored. (1) Introduction of new goods creates a first order effect of "new good bias" if ignored. 5 (2) Quality changes in existing goods will lead to "quality" bias, which has first order effects on a COLI. ${ }^{6}$ (3) Shifts in shopping patterns to lower priced stores can create first order "outlet bias". ${ }^{7}$ However, none of these first order effects can be measured correctly by price changes alone. Thus, the current BLS data collection approach where the BLS collects only price data cannot correctly take account of these first order biases. ${ }^{8}$

Consider an example where both quality and price increase for an existing good. Yet, consumers buy more of the good. Our London social reformer, and the current BLS procedure for most goods, would find that the price index had increased or stayed the same. However, it is quite likely that a correctly measured COLI would decrease. The social reformer would have no approach for new goods, again in common with the BLS. She would put them into the basket at the current price and wait for the price to change, which is the BLS procedure. Often, much of the increase in consumer welfare from introduction of the new good, which should be included in a proper COLI, will never be

\footnotetext{
${ }^{4}$ By first and second order effects, I mean the term that arises in a Taylor expansion of the COLI as I demonstrate subsequently.

${ }^{5}$ Marshall (1887) discussed problems in measuring the cost of living arising from the introduction of new goods

${ }^{6}$ Sidgwick (1883) discussed the problem of quality change.

${ }^{7}$ Recent immigration in the east end of London may have led to new stores that charged less than the existing retail outlets.

${ }^{8}$ The BLS periodically collects expenditure (quantity) data to estimate the weights that enter the CPI. However, the BLS would need to collect quantity data at high frequency, similar to collection of price data, to take account of these three sources of bias.
} 
measured by the BLS. ${ }^{9}$ Lastly, for shifts in shopping patterns if a consumer pays less for identical goods the COLI would typically decrease. Success of new outlets, such as WalMart, which now sells approximately $10 \%-15 \%$ of many branded consumer products and is the largest supermarket chain in the US, would attest to the economic importance to consumers of lower prices. ${ }^{10}$ While the social reformer would take account, in a simple unweighted average, of the prices of the new outlets, she would not take account of the shift in spending to the new outlets. Again, her approach and the BLS approach would be the same creation of first order biases.

I explain in this paper that a "pure price" based approach of surveying prices to estimate a COLI cannot succeed in solving the 3 problems of first order bias that I have discussed. The recent report by the Committee on National Statistics (Committee), C. Schultze and C. Mackie, eds., At What Price (AWP, 2002), recognizes the existence of these problems, which have been long known, but it does not recommend correct approaches to deal with them. ${ }^{11}$

Any correct approach to incorporating these issues into a COLI must take account of both quantities and prices. ${ }^{12}$ By failing to recognize this fundamental point, the Committee has failed to recommend an approach to the BLS that would lead to a COLI approach for the $21^{\text {st }}$ century. Instead, the Committee has recommended solutions to

\footnotetext{
${ }^{9}$ For cellular telephones where it took the BLS 15 years to introduce them into the CPI, see Hausman (1999).

${ }^{10}$ Wal-Mart's sales for 2001 for the following companies were: Gillette 12\%, Proctor and Gamble 15\%, and Revlon $19.9 \%$.

${ }^{11}$ The study was funded by the BLS. The Committee basically accepts the current BLS approaches to these problems.

${ }^{12}$ Diewert (1998) and Hausman (1999) have both previous emphasized the importance of quantity data. Alternatively, expenditures and prices will yield the similar information to quantities and prices.
} 
second order problems of the early $20^{\text {th }}$ century, which will lead to minor improvements in the original $19^{\text {th }}$ century approach to price index estimation. ${ }^{13}$

In the $19^{\text {th }}$ century quantities sold could not be economically measured.

However, beginning in about 1985 as bar code scanners (developed in part at MIT) became common in US retail outlets, two companies, AC Nielsen and IRI, began collecting price and quantity data in great detail from retail outlets. ${ }^{14}$ Almost every retail outlet is now computerized, and its prices and quantities are recorded and often collected and re-sold to manufacturers. Supermarkets, neighborhood convenience stores, pharmacies, and "big-box" (Circuit City) retail outlets all have data that can be purchased from vendors. ${ }^{15}$ Thus, the quantity data needed to estimate a "modern" COLI is in large part available. ${ }^{16}$ My suggestion would be for the BLS to begin to collect these quantity and price data and for the BLS to research and develop methods to collect quantity data where it does not currently exist. ${ }^{17}$ Sending price surveyors out to stores, which is the main approach used by the BLS as with the $19^{\text {th }}$ century social reformer, will not get the job done in the 21 st century. ${ }^{18}$

\footnotetext{
${ }^{13}$ I discussed the requirement to collect quantity data to estimate a correct cost of living index in Hausman (1999).

${ }^{14}$ These companies gather the information at the SKU (stock keeping unit) level so that not only is the exact product known, e.g. Apple Cinnamon Cheerios, but the package size and type is also known along with the price.

${ }^{15}$ Family purchases in terms of prices and quantities for a random sample of households are also available. Thus, while the Committee's worried that the consumer expenditure survey is inaccurate (AWP p. 253), it did not explore the use of electronic collection of family expenditure data that is currently ongoing.

${ }^{16}$ Furthermore, these data are collected in "real time." The Committee repeatedly emphasizes the 2-3 year delay associated with collection of expenditure or quantity data (e.g. AWP p. 57). Scanner data are available almost immediately and could be incorporated into a price index without a 2-3 year delay. ${ }^{17}$ The BLS has done limited experimentation with scanning data, but has not yet realized that both price and quantity data are crucial to correct estimation of a CPI. See Silver and Heravi (2001a,b) for results using of scanner data in the UK and its effect on the calculation of traditional price indices.

${ }^{18}$ The Committee discusses the use of scanner data within the current BLS framework (AWP pp. 266ff). The Committee has only a very brief discussion (AWP pp. 273ff) regarding using scanner data to decrease biases in the CPI which I will discuss subsequently without the recognition of the requirement of using quantity data to reduce bias.
} 


\section{Evaluation of Biases in the CPI}

I conduct all my analysis in terms of a cost of living index (COLI), not a "price index". ${ }^{19}$ A COLI is the correct theoretical tool to measure the effect on consumer welfare of price changes, quality changes, and introduction of new goods, as the academic literature has long noted and as the BLS has recognized. ${ }^{20}$ Thus, I define the COLI based on the expenditure function, which is defined as the minimum income required for a consumer to reach a given utility level:

$$
y=e\left(p_{1}, p_{2}, \ldots, p_{n} ; \bar{u}\right)=e(p, \bar{u}) \text { solves } \min \sum_{i} p_{i} q_{i} \text { such that } u(x)=\bar{u}
$$

where there are $\mathrm{n}$ goods labeled $\mathrm{q}_{\mathrm{i}}$. The expenditure function arises either from the consumer demand functions through integration or from the constrained maximization of the direct utility function $\mathrm{u}(\mathrm{x})$, using duality theory. ${ }^{21}$ The change in the required income when, for instance, price change between period 1 and period 2, follows from the compensating variation $(\mathrm{CV}):^{22}$

$$
y^{2}\left(p^{2}, u^{1}\right)-y^{1}=C V=e\left(p^{2}, u^{1}\right)-e\left(p^{1}, u^{1}\right)
$$

\footnotetext{
${ }^{19}$ The Boskin (1996) Commission recommendation was that the BLS approximate a COLI as closely as possible. The Committee also finds that a conditional (on environmental background factors) COLI provides the correct concept for the CPI (AWP p. 73). I do not debate the political economy question of what is the appropriate index to use for government benefit programs, e.g. Social Security. I find it unfortunate that many economists have interpreted the Boskin (1996) Report as a "Republican" view of the CPI and the Committee Report as the "Democratic" response, see e.g. Madrick (2001), whose recommendation the Committee uses on the front cover of its book. Some of the Committee analysis seems designed to counter the Boskin (1996) report and defend the BLS approach.

${ }^{20}$ See e.g. Pollak (1988) and for the BLS view see e.g. Abraham et. al. (1998). The Committee (2002) has an extensive discussion of the theoretical basis of the COLI: AWP, chapter 2.

${ }^{21}$ Most modern micro textbooks discuss duality theory. See e.g. Deaton and Muellbauer (1980). For econometric methods estimating the expenditure function from the estimated demand function see e.g. Hausman (1981) and Hausman and Newey (1995).

${ }^{22}$ Superscripts denote the period and subscripts number the goods.
} 
The exact cost of living index becomes $P\left(p^{2}, p^{1}, u^{1}\right)=y^{2}\left(p^{2}, u^{1}\right) / y^{1}$ which gives the ratio of the required amount of income at period 2 prices to be as well off as in period 1. As with any index number calculation, the period two utility level, $\mathrm{u}^{2}$, allows for a different basis to calculate the cost of living index.

\section{The Effect of New Goods and Services on a COLI: New Good Bias}

Many new products and services have a significant effect on consumer welfare. For example, in Hausman (1997a, 1999, 2002) I have estimated that the gain in consumer welfare from the introduction of cellular telephone in the U.S. exceeded $\$ 50$ billion per year in 1994 and \$111 billion per year in 1999. As I now demonstrate new goods should be included in calculation of a COLI, where they have a first order effect. However, the BLS omits the effect of the introduction of new goods in its calculation of the CPI, thus imparting an upward bias. ${ }^{23}$ The Committee recommends that the BLS continue its current practice of excluding the effect of new goods in the CPI ( $\underline{A W P}$, p. 160).

\section{A. Using a "Virtual Price" to Estimate the Effect of a New Good}

I explain how new goods should be included using the classical theory of Hicks (1940) and Rothbarth (1941) that I have applied in Hausman (1996, 1997a, 1999, 2002). ${ }^{24}$ I discuss why quantity data are required to include the effect of new goods in a COLI and demonstrate that exclusion of the effect of new goods creates a first order bias in a COLI.

\footnotetext{
${ }^{23}$ When goods disappear from the market, the opposite first order effect occurs. However, typically only unsuccessful (unprofitable) goods disappear, and their negative effect on consumer welfare will typically be small as I demonstrate in Hausman (1999). The methodology developed here can be used to measure the negative effect on economic welfare from the disappearance of goods from the market.

${ }^{24}$ Diewert (1980) has an early discussion of the Hick's approach to new goods.
} 
As Hicks (1940) demonstrated, the correct price to use for the new good in the pre-introduction period is the "virtual" price, which sets demand to zero. Estimation of this virtual price requires estimation of a demand function, which in turn provides the expenditure function, which allows exact calculation of the COLI. Given the demand function I can solve for the virtual price and for the expenditure function and make correct evaluations of consumer welfare and the change in the COLI from the introduction of a new product or service. In period 1 consider the demand for the new good, $\mathrm{x}_{\mathrm{n}}$, as a function of all prices and income, $\mathrm{y}, q_{n}{ }^{1}=g_{n}\left(p_{1}{ }^{1}, p_{2}{ }^{1}, \ldots, p_{n-1}{ }^{1}, p_{n}{ }^{1}, y^{1}\right)$. Now if the good were not available in period 1 I solve for the virtual price, $p^{*}$, which causes the demand for the new good to be equal to zero,

$$
0=q_{n}{ }^{1}=g_{n}\left(p_{1}{ }^{1}, p_{2}{ }^{1}, \ldots, p_{n-1}{ }^{1}, p_{n}{ }^{*}, y^{1}\right)
$$

However, instead of using the Marshallian demand curve approach of Hicks (1940) and Rothbarth (1941) in equation (2.1), I instead use the income compensated and utility constant Hicksian demand curve to do an exact welfare evaluation. ${ }^{25}$ Income, y, is solved in terms of the utility level, $u^{1}$, to find the Hicksian demand curve given the Marshallian demand curve specification.

In terms of the expenditure function I solve the differential equation from Roy's identity which corresponds to the demand function to find the (partial) expenditure function, using the techniques that I developed in Hausman (1981). The approach solves the differential equation, which arises from Roy's identity in the case of common

\footnotetext{
${ }^{25}$ Estimation of the Marshallian demand curve provides the necessary information to calculate the Hicksian demand curve.
} 
parametric specifications of demand. To solve for the amount of income needed to achieve utility level $\mathrm{u}^{1}$ in the absence of the new good, I use the expenditure function to calculate $\mathrm{y}^{*}$, which is the required income to reach the reference utility level $\mathrm{u}^{1}$.

The effect on the correctly calculated COLI is "first order" because using Taylor's theorem: ${ }^{26}$

$$
y^{1}-y^{*}=\left(p_{n} *-p^{1}{ }_{n}\right) h_{n}\left(p^{\#}, u^{1}\right)=\left(p_{n} *-p^{1}{ }_{n}\right) \frac{\partial e\left(p^{\#}, u^{1}\right)}{\partial p_{n}} \quad \text { for } p^{\#} \in\left(p^{*}, p^{1}\right)
$$

where the Marshallian demand for the new good equals the compensated Hicksian demand, $q_{n}\left(p^{1}, y^{1}\right)=h_{n}\left(p^{1}, u^{1}\right)$. Alternatively, equation (3.2) measures the area under the compensated demand curve fore the new good or service, which yields a first order magnitude as illustrated in Figure 1. The exact cost of living index becomes $\mathrm{P}\left(\mathrm{p}^{1}, \mathrm{p}^{*}, \mathrm{u}^{1}\right)$ $=y^{*} / y^{1}$.

Note that to use this approach one must estimate a demand curve, which in turn implies the expenditure function and the ability to do the exact welfare calculation of equations (1.2) and (1.3). Thus, the only required assumption is to specify a parametric form of the demand function as in Hausman $(1981,1996,1999)$. Alternatively, estimation of a non-parametric demand curve could be used with welfare calculations following the approach of Hausman-Newey (1995). To estimate either a parametric demand curve or non-parametric demand curve, both price and quantity data are required. This requirement of quantity data is the basis for my recommendation that the BLS collect price and quantity data if it wants to estimate an accurate COLI.

\footnotetext{
${ }^{26}$ By "first order" I mean the leading term in a Taylor approximation to the change in the COLI.
} 


\section{B. A Simplified Approach to Estimate the Effect of a New Good}

Estimation of the expenditure function in equation (1.2) as well as $\mathrm{y}^{*}$ typically requires significant amounts of data and estimation of a demand curve. Compared to the usual BLS procedure in estimating the CPI, this approach using features of a demand function is considerably more complicated. However, estimation of the demand function for a new product (or equivalently a utility or expenditure function) is a necessary approach to estimation of $\mathrm{y}^{*}$, so that traditional Laspeyres index number formula or superlative formulae such as a Fisher index will not suffice in this situation.

I now propose a conservative approach that decreases the information requirements and should provide a "lower bound" estimate, which I have applied in Hausman $(1996,1997 \mathrm{a}, 1999)$. Once the demand curve is estimated, an approximation can be used by taking the supporting hyperplane at the observed price and quantities, $\left(p_{n}{ }^{1}, q_{n}{ }^{1}\right)$, which then leads to an estimate of the virtual price of the lower bound linear demand curve to the actual demand curve as illustrated in Figure 1. I claim that this estimate is conservative because the estimated virtual price from the linear demand curve will be less than the virtual price from the actual demand curve, unless the "true" demand curve is concave to the origin, which while theoretically possible would not be expected to occur for most new products and services. The change in expenditure to hold utility constant with the introduction of the new product, $\mathrm{y}^{1}-\mathrm{y}^{*}$, is the compensating variation which again can be approximated by the area under the approximate demand curve above the observed price.

This amount is easily computed (for the linear demand curve) as

$$
y^{1}-y^{*} \approx C S=\left(0.5 p_{n} q_{n}\right) / \alpha_{n}
$$


where CS is the consumers surplus from the introduction of the new product and $\alpha_{n}$ is the own price elasticity of demand. In terms of the virtual price, $\rho_{n}{ }^{*}=p_{n}{ }^{1}\left(\alpha_{n}+1\right) / \alpha_{n}$. To estimate equation the compensating variation current revenue $R_{n}=p_{n} q_{n}$ is required. Again, this approach emphasizes the need for both price and quantity data. The only econometric estimate needed is for the price elasticity $\alpha_{n}$, and this parameter appears to be the irreducible feature of the demand curve that is needed to estimate the change in the COLI from the introduction of a new product or service. ${ }^{27}$

\section{The Likely Importance of New Goods in a Correctly Measured COLI}

I next demonstrate that the introduction of new goods is likely to have a significant effect on a correctly calculated COLI. In my first new good paper, Hausman (1996) I demonstrated that significant welfare gains arose from the introduction of Apple Cinnamon Cheerios. ${ }^{28}$ Petrin (2002) finds large consumer effects from the introduction of minivans. While some economists have claimed that the introduction of many new goods typically do not benefit consumers, I demonstrate that market facts and economically rational behavior by firms demonstrates that new goods are likely to significantly benefit consumers. ${ }^{29}$ I call this outcome the "invisible hand of imperfect competition": when firms introduce new products in the expectation of making economic

\footnotetext{
${ }^{27}$ Other means of estimate the own price elasticity exist besides formal econometric estimation of a demand curve. All of the approaches require both price and quantity data, which follows from the definition of a price elasticity.

${ }^{28}$ See Hausman-Leonard (2002) for a recent estimation for estimation of the consumer welfare gains from another new consumer product.

${ }^{29}$ See e.g. Bresnahan (1997) in his comment to my cereal paper.
} 
profits (beyond their investment cost), significant consumers surplus will also be created. $^{30}$

It is a market fact that companies spend large sums of money introducing hundreds of new goods into the economy each year. The cost of introducing a new product is typically in the tens of millions of dollars and may exceed $\$ 100$ million. Most of these costs are sunk so that the firm must expect to earn sufficient profits (producers surplus) to recoup its investment in the new product introduction. While many new product introductions fail, a sufficient number succeed to make the investment profitable in a risk adjusted expected value sense.

I use common forms of a demand specification to demonstrate the effect on consumers, but the demonstration holds more generally. I begin with a constant elasticity demand curve and constant marginal costs, $\mathrm{MC}$, while holding prices of other products constant. ${ }^{31}$ Consumers surplus for the price elasticity (in absolute value) $\eta>1$ is $C S=p q /(\eta-1) .{ }^{32}$ Calculating marginal profit with constant marginal cost, $\mathrm{MC}=\mathrm{c}$, and using the first order conditions (FOC) that set $(p-c)=(p / \eta)$, the firm's profits (producers surplus) equal $\Pi=p q / \eta$. Note that if the demand elasticity $\eta$ is very large, the firm cannot earn significant marginal profits to earn back its sunk cost investment in the new good. Also, note the close relationship between the measure of consumer surplus

\footnotetext{
${ }^{30}$ While significant consumer benefit will arise, social welfare need not increase because much of the producers surplus for the firm introducing the new good may arise from the "business stealing" effect from other firms, as discussed e.g. in Spence (1976) and the numerous papers that have followed.

${ }^{31}$ The usual outcome is that the pries for substitute products will decrease so that consumers surplus will increase even more than this calculation. For an example with this outcome see Hausman-Leonard (2002). However, a multi-product firms that introduces a new product may be able to increase prices of its other products as I demonstrate in Hausman (1996), which creates an offsetting effect.

${ }^{32}$ Note that I am calculating the consumers surplus, rather than the compensating variation (CV) to keep the arithmetic straightforward. The finding holds also when the CV is used. Without loss of generality I have chosen units that set the constant in the demand function equal to unity. In imperfect competition the firm price elasticity of demand for each product will typically exceed unity in magnitude.
} 
and profits. This result creates the "invisible hand result of imperfect competition" since a moderate price elasticity leads to significant consumers surplus if the good is successful.

Now in expectation the firm has profits $\Pi \geq F$ where $\mathrm{F}$ is the fixed cost for introducing and advertising the product. F is usually between $\$ 30-100$ million, and sometimes higher. Rearranging and using the FOC, the firm's profits $\Pi=(C S / \delta)$ where $\delta=\eta /(\eta-1)>1$. Therefore I find that consumers surplus exceeds the fixed costs of introduction since $C S=\delta \Pi \geq \delta F \geq F$. Thus, consumers surplus from successful new products must be high for this demand formulation or firms would not introduce them since they could not cover their fixed costs. ${ }^{33}$

Among a flexible (Box-Cox) family of demand specifications the constant elasticity demand function yields the highest CS. The linear demand function yields the lowest CS as I discussed previously. Repeating the analysis for the linear demand function $C S=p q / 2 \eta$. From the FOC as in equation (2), it follows that $\Pi=p q / \eta$. Thus, for the linear demand curve I find $C S=0.5 \Pi \geq 0.5 F$. Thus, the minimum expected consumers surplus is $1 / 2$ of fixed costs, which is usually a significant amount. Indeed, this relationship gives a lower bound for expected consumers surplus for all demand specifications that are concave to the origin.

A caveat should be mentioned. The demand curve could become horizontal or near horizontal at given price where a competing good is equivalent in quality and lower

\footnotetext{
${ }^{33}$ This economic analysis demonstrates that Bresnahan's (1997) doubts about the value of new goods, to which the Committee refers (AWP, p. 160) is inconsistent with observed market behavior by profitmaximizing rational economic firms. An alternative way to consider the question is with nearly flat (high $\eta$ ) demand curves, the consumers surplus would be small, but the firm could not earn sufficient marginal profits to pay for its fixed cost investment. Note that the fixed costs must be earned back over the lifetime of the product. However, firms also spend significant fixed costs each year for branded products, e.g. advertising costs.
} 
in price as in vertical differentiation, e.g. a kink point would exist in the demand curve. Then the demand curve would not be concave to the origin. For most new differentiated products, I expect this outcome to be unlikely since brand name has a significant role in demand. Thus, the "invisible hand of imperfect competition" will typically lead to significant welfare gains from new product introduction, or otherwise, firms would not find it economically rational to introduce new products. Omission of the effects of the introduction of new goods by the BLS is likely to create substantial downward bias in the CPI.

\section{The Effects of Quality Change on a COLI: Quality Change Bias}

I now consider the effects of quality changes on a COLI. The BLS either does not adjust for quality change (using a "matching procedure" to link in goods with quality change) or for some products uses a hedonic adjustment procedure, which I discuss subsequently. The economic theory of quality change arises in a similar way as the new good analysis that I discussed in the last section. Here, I assume that good n (old quality) exists in period 1 while good $\mathrm{n}+1$ (new quality) exists in period 2. The difference in expenditure functions yield the $\mathrm{CV}$, which is the difference in areas under the two Hicksian compensated demand curves as illustrated in Figure $2:^{34}$

$$
y^{2}-y^{1}=C V=e\left(p_{1}{ }^{1}, \ldots, p_{n-1}{ }^{1}, p_{n}{ }^{*}, p_{n+1}, u^{1}\right)-e\left(p_{1}{ }^{1}, \ldots, p_{n-1}{ }^{1}, p_{n}, p_{n+1}{ }^{*}, u^{1}\right)
$$

\footnotetext{
${ }^{34}$ I am keeping all other prices the same between the two periods. Prices of other goods in period 2 may differ from period 1, but equation (4.1) can be used and then other prices in period 2 can be changed. The order of the change does not matter because of integrability. For a discussion see e.g. Hausman (1981) or Hausman-Newey (1995).
} 
where $p_{n}{ }^{*}$ and $p_{n+1}{ }^{*}$ are the virtual prices that set demand to zero. The difference between the two expenditure functions typically is a first order effect, as I demonstrated in equation (2.1). Thus, omission of quality change leads to a first order bias in the estimation of a COLI. I provide an example of this approach in the appendix. To estimate the effect of a quality change on a COLI, again quantity data will be required.

A (lower bound) approximation, holding the price of the product constant, could again be used to compute: ${ }^{35}$

(3.2) $y-y^{*} \approx C V \approx \frac{0.5\left(p_{n}{ }^{1} q_{n}{ }^{2}-p_{n}{ }^{1} q_{n}{ }^{1}\right)}{\alpha_{n}}=\frac{0.5 p^{1}\left(q_{n}{ }^{2}-q_{n}{ }^{1}\right)}{\alpha_{n}}=\frac{\left(p_{n}{ }^{*}-p_{n}{ }^{1}\right)\left(q_{n}{ }^{2}-q_{n}{ }^{1}\right)}{2}$ where $p_{n}{ }^{*}=p_{n}{ }^{1}\left(\alpha_{n}+1\right) / \alpha_{n}$. If the price does not change, the estimate is the change in quantity times the price adjusted with the demand elasticity. If the price also changes, using equation (3.2), I find

$$
C V \approx 0.5\left[p_{n}^{*}\left(q_{n}^{2}-q_{n}^{1}\right)-\left(p_{n}{ }^{2} q_{n}{ }^{2}-p_{n}{ }^{1} q_{n}{ }^{1}\right)\right]
$$

so that the change in consumer welfare arises from the increase in quantity purchased minus the difference in expenditure for the new quality product minus the difference in expenditure for the previous quality product. In general, the net result of both a quantity increase due to a shift of the demand curve and a price increase can either increase or

\footnotetext{
${ }^{35}$ This approximation gives a lower bound for the effect of quality change under the assumptions of a linear demand curve (as before) and the assumption that the new good with improved quality always has higher demand than the old quality good at each price (their virtual price is assumed to be the same).
} 
decrease the COLI. Again, we see the first order effect of a quality change and the requirement to measure quantities to estimate the $\mathrm{CV}$ or change in the COLI.

This analysis also demonstrates that a recommendation of the Committee that the BLS should endeavor to introduce new goods into the CPI earlier, since the BLS did not include cellular telephones until 15 years after their introduction in the U.S., only solves part of the problem. It does not really solve the problem of quality change. The result is still an upward bias in the estimate of the CPI because the increase in the COLI due to quality change, as with cellular phones that became smaller, more reliable, with longer battery life, and more convenient to use, would be totally missed. For an earlier year of introduction, $\mathrm{y}^{*}$ from equation (4.2) is smaller, but once cellular is introduced into the COLI the demand curve typically continues to shift outwards for a significant period of time. This outward shift in the demand curve caused by increased quality and diffusion creates additional consumer welfare, which would be incorporated into a COLI through equation (4.2). Still, much more frequent updates of expenditure weights in the CPI would help alleviate the current problem. This change has been recommended by many economists; see e.g. the Boskin (1996) report.

Thus, for many new goods in each year two effects are present: a decreased price for the given demand curve and an outward shift of the demand curve holding price constant. Because of the use of Hicksian compensated demand functions and expenditure functions in the calculations, the combined effect of the two economic factors is path (year of introduction) independent. Introduction of new goods and improved quality of existing goods are actually similar economic effects, which enter a COLI in a similar manner. This discussion demonstrates why in the presence of the introduction of new 
goods and quality improvement (or quality deterioration) of existing goods both prices and quantities (or revenues) must be used to calculate a correct COLI. The BLS approach of only using prices and ignoring the information in quantity data will never allow for a correct estimate of a COLI in the presence of new goods and improvements in existing goods. ${ }^{36}$

\section{The Effect of Lower Price Stores: Outlet Bias}

An important market outcome in retailing over the past 30 years is the growth of discount retail outlets such as Wal-Mart and Best Buy and Circuit City for durables. Wal-Mart is now the largest supermarket chain in the U.S. and for a number of branded goods it now sells $10 \%-20 \%$ of the output of large branded companies. These outlets offer significantly lower prices than "traditional" outlets such as department stores. The lower prices cause a first order effect in a COLI when consumers shift their shopping patterns away from traditional outlets to these rapidly growing discount outlets.

Obtaining current price and quantity data from these outlets would be straightforward since they all employ scanner technology.

The lower prices create a first order welfare increase in a COLI using the expenditure function because the derivative of the expenditure function with respect to a change in price equals the quantity purchased, which is a first order effect. ${ }^{37}$ This result demonstrates the first order effect of lower outlet prices for identical products. The result also demonstrates the requirement to measure the quantity purchased in the discount

\footnotetext{
${ }^{36}$ The quality of goods may also decrease. The analysis would be the same.

${ }^{37}$ This result is known as "Sheppard's Lemma", see e.g. Deaton and Muellbauer (1980).
} 
outlets. Thus, only knowing the prices at the discount outlet does not give the needed information.

While the Committee recognizes the possibility of "outlet bias", it recommends ignoring this first order problem. It agrees with the implicit BLS assumption that the difference in service quality lead to an equilibration of a "service adjusted" price. This argument fails on at least two grounds. First, the shareholders of Wal-Mart would be amazed to find that consumers are indifferent between shopping at Wal-Mart and shopping at traditional outlets, given Wal-Mart's phenomenal growth over the years. ${ }^{38}$ Also, many consumers place a lower value on their time spent shopping as the recent dotcom e-commerce "B to C" (business to consumer) failures demonstrate. Thus, the market evidence goes completely against the Committee's unsupported claim that outlet bias is not an important factor in a correct calculation of a COLI and its recommendation that the BLS continue its current procedure (AWP p. 176). When the discount stores are gaining market share, then this market outcome is evidence of an outlet substitution effect that should not be ignored by the BLS.

\section{The Effect of Price Change: Substitution Bias}

Lastly, I come to substitution bias, a second order effect, that the Committee spends much of it effort in recommending that the BLS address. Using a Taylor approximation around the period one price, when only price $\mathrm{j}$ changes, I rewrite equation (1.2) as ${ }^{39}$

\footnotetext{
${ }^{38}$ Wal-Mart's lower prices are in part related to superior logistical systems that have nothing to do with lower service quality levels.

${ }^{39}$ All other prices re assumed to remain constant except for the jth price.
} 


$$
\begin{aligned}
& y^{2}-y^{1} \approx\left(p_{j}{ }^{2}-p_{j}{ }^{1}\right) h_{j}\left(p^{1}, u^{1}\right)+\frac{1}{2}\left(p_{j}{ }^{2}-p_{j}{ }^{1}\right)^{2} \frac{\partial h_{j}\left(p^{1}, u^{1}\right)}{\partial p_{j}} \\
& =\left(p_{j}{ }^{2}-p_{j}{ }^{1}\right) q_{j}\left(p^{1}, y^{1}\right)+\frac{1}{2}\left(p_{j}{ }^{2}-p_{j}{ }^{1}\right)^{2} \frac{\partial h_{j}\left(p^{1}, y^{1}\right)}{\partial p_{j}}
\end{aligned}
$$

For each given form of expenditure function, or equivalently the demand functions $\mathrm{h}$ and $\mathrm{q}$, there exists a given $p_{j}{ }^{\#} \in\left(p^{1}, p^{2}\right)$ that makes equation (4.1) hold with exact equality. This expression is the basis for Diewert's (1976) notion of a superlative index. ${ }^{40}$ The analysis also explains why Irving Fisher's (1922) geometric mean approach for period one and period two prices and numerous other approaches will all approximate some expenditure (utility) function up to second order. The first term (the first order term) is taken account of in the current CPI, but the "substitution bias" arises from the second order term as is illustrated in Figure $3 .^{41}$ I would not claim that the second order terms are not important — since prices change over all n goods the sum of the second order substitution effects could be important. ${ }^{42}$ However, I do find it a rather strange outcome when the Committee recommends a partial correction to the substitution bias effect, which is second order, while the Committee recommends the BLS made no attempted correction to the first order effects that I discussed above. Also, calculation of all

\footnotetext{
${ }^{40}$ A superlative price index is one that is exact for some second-order flexible function for a homothetic utility (expenditure) function. Note that the Diewert approach to second order approximations require the assumption of a homothetic utility function so all expenditure elasticities are assumed to be unity. This assumption is well known not to hold in practice. Alternatively, homotheticity can be eliminated if the reference utility level is changed to a geometric average of the reference utilities in the two periods.

${ }^{41}$ The second term is "second order" because it is the product of a change price times a change in quantity. It is equivalent to what is often called a "Harberger triangle" used to measure deadweight loss See Hausman (1981) for a further discussion on the accuracy of measuring this deadweight loss amount. More generally, if all prices change the derivatives of the compensated demands with respect to prices are the terms in the Slutsky matrix.

${ }^{42}$ A recent empirical investigation by Shapiro and Wilcox (1997) found moderate bias of about $0.3 \%$ per year caused by the substitution effect.
} 
superlative indices requires quantity (expenditure) information in both period 1 and period $2 .^{43}$

\section{Current BLS Approach to Quality Change: Hedonic Regressions}

The current BLS approach to quality change for most goods is to ignore it. Instead the new product is matched to an existing product, and a linking procedure follows. The results can be problematic. For example, when Windows 95 was introduced, it replaced the combination of MS-Dos and Windows 3.1. Windows 95 had much superior functionality. The BLS procedure would lead to introduction of the product with no quality adjustment compared to the existing operating systems. However, market evidence demonstrates that most consumers were better off because they purchased Windows 95 when they could have continued to purchase MS-DOS/Windows 3.1 at a lower price. Thus, the BLS procedure would lead to an upward bias in the CPI.

For a small number of goods, e.g. PCs, the BLS has used a hedonic adjustment for quality change. The BLS appears to be expanding its use of hedonics, as the BLS website list a number of "developmental" hedonic research programs for consumer durable goods. ${ }^{44}$ Unfortunately, I do not think that a hedonic approach is correct in general. It does not measure consumer preferences, which are the basis for an expenditure function and a COLI as demonstrated in equation (1.2). ${ }^{45}$ More generally,

\footnotetext{
${ }^{43}$ While the BLS will collect quantity data to account for substitution bias, they are only collecting expenditure data at the highest levels of aggregation; i.e., at the level of some 200 aggregate commodities. Thus this data base will not allow for estimation of new good bias, quality bias, or outlet bias.

${ }^{44}$ See http://www.bls.gov/cpi/home.htm. Hedonic adjustments for the following products are listed: clothes dryers, microwave ovens, college textbooks, VCRs, DVD players, camcorders, and consumer audio equipment.

${ }^{45}$ Diewert (2001) develops sufficient conditions to allow a hedonic regression to be interpreted as a function of consumer preferences. However, the assumptions, in my opinion, are too strong to be useful,
} 
since a hedonic approach only uses prices of products without using quantity data, it will not lead to the correct answer as I discussed above. I now discuss the hedonic adjustment approach.

\section{Hedonic Quality Adjustment}

The BLS has adopted the hedonic approach to adjust for quality changes for certain products such as computers. A hedonic regression has price (or log price) on the left hand side ("dependent variable") and product characteristics on the right hand side (RHS or "explanatory variables"). The basic idea is to estimate the coefficients of the RHS variables and then to adjust observed prices for changes in attributes. For example, suppose the regression has as a RHS variable the log of the microprocessor speed. Suppose that the price of a computer decreased by $10 \%$ over a year's time and its processor speed increased from $1.5 \mathrm{mHz}$ to $2.0 \mathrm{mHz}$. If other RHS variables had remained constant the estimated price decrease in percentage terms would approximately be $\hat{p}=-0.1-b^{*} 0.33$ where $\mathrm{b}$ is the estimated coefficient of processor speed in the estimated regression.

However, this hedonic regression adjustment has no simple relationship with consumer valuation of the computer, which is the correct basis for a COLI. The price of a good under imperfect competition is an interaction of three sets of economic factors: demand, cost, and competitive interaction. ${ }^{46}$ A hedonic regression mixes these three sets of factors together and is not estimating a structural relationship, which would permit them to be separated. The well-known instability of the estimated coefficients across

and I do not believe that the hedonic regression is identified in an econometric interpretation since the characteristics of the goods would be jointly endogenous with the price.

${ }^{46}$ Under very special conditions (perfect competition) only cost may matter in determination of the price. 
years for a hedonic regression on PCs demonstrates the absence of a structural relationship. ${ }^{47}$ In one very special case price does not depend on demand so a hedonic regression could identify the cost factor. However, this special case arises when no economies of scale or scope are present—essentially the conditions needed for the Samuelson-Mirrlees non-substitution theorems. ${ }^{48}$ An assumption of the absence of economies of scale and scope would not make sense in the PC industry. Further, the presence of imperfect competition, e.g. in the PC industry the presence of "brand effects" that are found to be empirically important in many hedonic regressions (e.g. PCs), gives another reason why in the PC industry hedonic regression are inappropriate to use to adjust prices. $^{49}$

The correct way to measure the effect of quality change for a COLI is to take account of demand changes that arise, as I discussed above. But to measure demand changes, quantities of the various models of PCs must be used. The hedonic approach to quality change and the BLS is attempting to use a "pure price" approach, which cannot measure the required compensating variation amount. ${ }^{50}$

I consider a situation where a good, which I take to be a given brand of personal computer (PC), has additively separable utility from consumption of other goods. I assume that a consumer derives utility from 2 features in a PC, to keep notation simple. The consumers' (partially indirect) utility function in period 1 is:

$$
v^{1}=m\left(x^{1}, z^{1}\right)+\left(y^{1}-p^{1}\right)=g_{1}\left(x^{1}\right)+g_{2}\left(z^{1}\right)+\left(y^{1}-p^{1}\right)
$$

\footnotetext{
${ }^{47}$ See e.g. Berndt et. al. (1995).

${ }^{48}$ I discuss this question at greater length in Hausman (2002b)

${ }^{49}$ Hausman (1996) discussed the importance of imperfect competition in new product entry and measurement of the effect of new goods on the CPI. Similar issues arise with quality improvement of existing goods.

${ }^{50}$ Hedonic demand functions that use quantity data could be estimated, which would allows for correct treatment of quality change.
} 
where $\mathrm{y}^{1}$ is income in period $1, \mathrm{p}^{1}$ is the price of the computer, and for ease of exposition I assume that the features, say microprocessor speed $(\mathrm{mHz})$ and hard drive capacity, enter separably into the utility function.

In period 2 the features change to $x^{2}$ and $z^{2}$. Assume, for ease of exposition, that income remains the same. To determine the CV solve for $C V=\Delta y$ that causes $v^{1}=v^{2}$. Because of the additive separability of equation (5.1) we solve for $p^{2^{\#}}$ that causes the equality to hold, $p^{2 \#}=p^{1}+g_{1}\left(x^{2}\right)-g_{1}\left(x^{2}\right)+g_{2}\left(z^{2}\right)-g_{2}\left(z^{2}\right)$. Thus, the new "quality adjusted" price is the old price $\mathrm{p}^{1}$ adjusted for changes in features, where the evaluation is done using the consumers' utility valuation.

In determining the market price of a particular PC, three factors enter the equilibrium solution: cost, demand and competition. ${ }^{51}$ In a Nash-Bertrand model of imperfect competition, which describes the PC industry, price would be set as:

$$
p^{1}=m^{1} * c^{1}=m^{1}\left[w_{1}{ }^{1} h_{1}\left(x^{1}\right)+w_{2}{ }^{1} h_{2}\left(z^{1}\right)\right]
$$

where $m$ is the markup over marginal cost $c^{1}$. The markup factor $m^{1}$ is determined by the own price demand elasticity, which in turn depends on competition (through the Slutsky relation). For example, in Nash-Bertrand competition for differentiated products for the PC model indexed by $\mathrm{j}, m_{j}{ }^{1}=\eta_{j} /\left(\eta_{j}-1\right)$ where $\eta_{j}>1$ is the (magnitude) of the own price elasticity. ${ }^{52}$ The $\mathrm{w}_{\mathrm{i}}$ are the "cost per unit" of the transformed units of the microprocessor speeds and hard drive capacity. ${ }^{53}$

\footnotetext{
${ }^{51}$ Pakes (2001) also discusses problems in interpreting a hedonic regression specification using these economic factors.

${ }^{52}$ Under perfect competition $\mathrm{m}=1$. For this derivation see e.g. Hausman, et. al., "Competitive Analysis with Differentiated Products," Annales, D'Economie et de Statistique, 34, 1994.

53 This discussion also demonstrates that the other BLS method of "cost-based adjustment" for quality change is also incorrect. The BLS uses this approach for automobiles, but the value to consumers is not
} 
Note that the $h_{i}$ are determine by technology, the $x^{1}$ and $z^{1}$ are determined by the interaction of consumers preferences, technology, and competition, and the $\mathrm{w}_{\mathrm{i}}$ are determined, by cost, demand, and competition in the factor input markets, e.g. competition between AMD and Intel for microprocessors. The $\mathrm{h}_{\mathrm{i}}$ are related to the $\mathrm{g}_{\mathrm{i}}$ which determine a consumers utility valuation of the components in a PC through a technology transformation function and demand and competition. ${ }^{54}$

A hedonic regression, as used by the BLS to adjust prices for quality changes, determines the price as a function of a product attributes. Demand and competition are not taken into account. I assume that the econometrician knows (or figures out) the $\mathrm{h}_{\mathrm{i}}$ functions and estimates the conditional expectation (regression function). The estimated coefficients will combine the markup, which would likely differ across firms unless $m=1$ (perfect competition) and the factor prices $\mathrm{w}_{\mathrm{i}}$. Thus, hedonic regressions are not structural equations since the markups are likely to change across time as are the factor input prices, the $\mathrm{w}_{\mathrm{i}}$. This derivation is consistent with the empirical evidence for PC hedonic regression that the coefficients change significantly across years, e.g. Berndt et. al (1995).

The hedonic adjustment for quality change in computer type $\mathrm{j}$ would yield

\footnotetext{
determined by the incremental costs. Further, the markup for cars, $m>1$, further demonstrates that the BLS approach is incorrect.

${ }^{54}$ To the extent that the choices of $\mathrm{h}_{\mathrm{i}}$ are in response to consumer preferences, an identification problem exists that does not allow for separation of consumer preferences and technology.
} 
has no straightforward relationship to the evaluation of $\mathrm{CV}$ to hold in equation (5.2).

Thus, price adjustment using hedonic price regression has no relationship, under general conditions, to what is supposed to be measured in a COLI. ${ }^{55}$

Two approaches would, in principle, lead to correct measurement of the CV to use in a COLI. (1) A demand system could be used to estimate demand for PCs in period 1. The $\mathrm{CV}$ can then be calculated as the change in the areas under the demand curves (consumers surplus) or more generally from the expenditure function estimated in period 1, as I discussed above. ${ }^{56}$ (2) A discrete choice demand system could be estimated where the left hand side variable is the share of model $\mathrm{j}$ in PC sales and equation (5.1) is estimated directly. The $\mathrm{CV}$ is estimated from equation (5.2). ${ }^{57}$ The important point to note is that either method requires quantity data so that estimates of the demand functions (or equivalently the expenditure or utility functions) can occur. Data on price and product attributes alone will not allow correct estimation of the $\mathrm{CV}$ adjustment to the COLI. ${ }^{58}$ Thus, our fictional data gatherer in London in the $19^{\text {th }}$ century, or the BLS today, must gather quantity data as well as price data to adjust for quality change. While the task may not have been possible in the $19^{\text {th }}$ century, it is possible today. However, the current approach of the BLS as well as the recommendations in the Committee report in At What Price will not lead to the correct approach.

\footnotetext{
${ }^{55}$ Under special condition of perfect competition and a particular demand function, equation (5.5) can be related to the appropriate consumer valuation. However, the assumptions are too special to be of any practical importance. In particular, perfect competition describes few, if any, real world markets. ${ }^{56}$ I used this approach for cellular telephones. See J. Hausman (1999).

${ }^{57}$ I used this approach for different models of air conditioners. See J. Hausman (1979). For a recent application to automobiles of this approach see Berry et. al. (1995).

${ }^{58}$ I disagree with the Committee's conclusion that hedonic methods are "probably the best hope" for improving quality adjustments (AWP p.64, p. 122), since hedonic methods are do not estimate consumer valuation of a product, and consumer demand is the basis of a COLI as I have demonstrated. Interestingly, the Committee recommends using the "direct method" of hedonic adjustment (AWP p.129) which requires high frequency data collection of prices and product attributes. If the BLS also collected quantity data at the same time, it could estimate the change in the COLI from quality change using methods I discussed in the last section or from equations (5.1) and (5.2).
} 
Furthermore, since I expect that for PCs, we would find that $g_{i}^{\prime}<m w_{i} h_{i}^{\prime}$ where the primes denote the derivatives, i.e. consumers get less marginal utility for a given increase in an attribute than the increase in marginal cost, the typical result is that the BLS adjustment for quality is too large for PCs. ${ }^{59}$ Thus, I would expect the result that the BLS hedonic adjustment for PCs has been too large and the price index for PCs used by the BLS is downward biased with respect to quality adjustments. However, in other markets for other products the inequality will likely go in the reverse direction, as I discuss below. The important conclusion is that for any particular product and market, the hedonic price adjustment does not measure the change in any COLI. Analysis of quantity data and price data could lead to a correct adjustment.

\section{Medical Goods and Services}

Medical goods and services create two special difficulties: measurement of outputs and technological change, which is especially rapid. The Committee determined that outcome-based measures should not be used. (AWP p. 188) The Committee recommends using diagnosis-based measures instead of input-based measures where feasible. This recommendation is an improvement, but it does not measure quality change. For example, improvements in treating breast cancer have been remarkable over the past decade. While the price has not decreased and may well have increased, given that survival times have increased significantly many families would be willing to pay a

\footnotetext{
${ }^{59}$ As an example, suppose in period 1 the hedonic regression measures microprocessor speed in log and a $50 \%$ increase in speed lead to a 10\% higher price for PCs. In period 2 a PC with the faster microprocessor speed would have its quality adjusted price reduced by $10 \%$ using the hedonic regression. My conjecture is that thee representative consumers' function $g\left(x^{1}\right)$ is unlikely to have increased by $10 \%$. If so, the quality adjustment is too large, leading to a downward biased estimate of the CPI.
} 
large amount of money for the improvement in survival probabilities. A correctly measured COLI would account for this improvement in outcomes.

Problems from the interaction of output measurement and technological change are especially striking for prescription drugs. For existing drugs with patent protection, price increases have generally been in line with the CPI over the past decade in the range of $2 \%-3 \%$ per year. When existing drugs come off patent, generic entry is usually rapid with a significant decrease in price for the generic drug. The CPI for prescription drugs increased by $4.4 \%$ in 2000 and $5.4 \%$ in 2001 . However, about 25 new drugs are approved each year. Many of these drugs sell substantial amounts, in the hundreds of million or billions of dollars per year. In a given year since it is extremely rare for an existing drug to exit the market, a consumer could continue to buy the old drugs. To the extent a consumer buys a new, and more expensive drug, for an illness, it is because she will be better off with the more expensive drug. ${ }^{60}$ Otherwise, she could buy the old, and less expensive, drugs. But the BLS nowhere takes account of this improvement in medical technology and outcomes. The BLS matching approach leads to an overestimate of the effect of price increases in prescription drugs because it does not account for improved quality. Nor would a hedonic approach typically be able to be used since an improvement such as "less side effects" would essentially be an indicator variable with no explanatory power. The correct approach would be take quantity into account to measure the compensating variation that goes into a correctly measured COLI. ${ }^{61}$ Again, until the BLS begins to take quantities into account, it will not be able to measure correctly the effects of medical products and services.

\footnotetext{
${ }^{60} \mathrm{I}$ am assuming that doctor's recommendations are aligned with the consumer's welfare. To calculate a COLI, a necessary assumption is that consumers make rational economic choices.

${ }^{61}$ Quantities of prescription drugs sold (and their prices) are readily available from commercial vendors.
} 


\section{Estimation of Overall Bias in the CPI}

The CPI is an extremely important tool for economic analysis. The CPI allows for changes of "nominal" measures into "real" (inflation adjusted) measures. As these terms suggest, the U.S. government should devote significant resources to the measurement of the CPI in terms of a COLI because our economic knowledge of consumer welfare depends, in large part, on accurate measurement. Evaluation of the bias in the CPI has been difficult with much of the debate based on a few select measurements, i.e. "analysis by anecdote." 62 Here I review some recently published research that estimates the bias in the CPI by considering aggregate consumption data. This analysis, while not definitive, is suggestive of substantial upward bias in the BLS CPI. The Committee report did not address this research in its evaluation of the magnitude of the bias in the CPI.

Costa (2001) and Hamilton (2001) estimate bias in the CPI by using expenditure survey data to estimate the increase in households' expenditures versus their real income over time. This procedure will capture "outlet bias" and "substitution bias", but it will not measure either "new good bias" or "quality change" bias. To the extent that most (all) economists would agree that net quality change has been an improvement over time, the Costa and Hamilton approaches will yield an under-estimate of CPI bias.

The basic empirical methodology is to compare households with similar demographic characteristics and the same real income at different points in time and

\footnotetext{
${ }^{62}$ Indeed, the debate is similar to some court proceedings where the Court decides based on chosen examples that the opposing sides present, rather than a systematic analysis of the data.
} 
compare their expenditures of given categories of expenditure. ${ }^{63}$ Costa (2001) uses food and recreation expenditures. Using data from 1972-1994 Costa finds that cumulate CPI bias during this period was $38.4 \%$ with an annual bias of $1.6 \%$ per year. ${ }^{64}$ Hamilton (2001) also estimates CPI bias to be $1.6 \%$ per year during this period, using a similar econometric approach on a different data set. This sizeable estimate of bias demonstrates how the BLS procedure over estimates the COLI. The actual bias would be even greater if the effect of new goods bias and quality change bias were included. ${ }^{65}$

A recent estimate of quality growth by Bils and Klenow (2001) finds a significant estimate of quality bias over the period $1980-1996 .^{66}$ They estimate that the BLS understated quality improvement and overstate inflation by $2.2 \%$ per year on products that constituted over $80 \%$ of US spending on consumer durables. ${ }^{67}$ These more aggregate studies along with my (and other) micro studies on particular goods demonstrate that CPI bias is likely to be substantial.

The Committee in AWP does not recommend solutions to these bias problems. Until the BLS incorporates quantity data into their data collection and estimation procedure, these sources of bias will continue to exist in the CPI. The magnitude of the biases are much too large to be ignored. New goods bias, quality bias, and outlet bias are

\footnotetext{
${ }^{63}$ The identifying assumption, besides functional form, is that the expenditure elasticities remain constant over time for a given category of expenditure after controlling for demographic characteristics. Thus, residuals from the relationship between real income and predicted expenditures are used to estimate the bias in prices that are used to deflate income.

${ }^{64}$ Costa's estimates of annual bias range from $1.4 \%$ to $2.6 \%$ per year over this period.

${ }^{65}$ The Boskin Report (1996) estimated that these two sources of bias were the largest source of bias in the CPI during the 1975-1994 period.

${ }^{66}$ They use expenditure data on durable goods, which takes account of the quantities purchased as I discussed above.

${ }^{67}$ Bils and Klenow use a constant elasticity of substitution specification, which with its implication of the independence of irrelevant alternatives, may yield an over estimate of quality change as I discuss in Hausman (1996).
} 
first order biases in the CPI, which the BLS does not correctly adjust for. The BLS should begin to develop methods that account for these biases. 


\section{Appendix}

\section{Estimating the Effect of a Quality Change}

I demonstrate the effect of quality change on a particular example. To calculate the expenditure function of equation (3.4), as an example, I use the results of Hausman (1981) for a constant elasticity demand curve to calculate

(A.1) $e\left(p, u^{1}\right)=\left[(1-\delta)\left(u^{1}+A p_{n}{ }^{1+\alpha} /(1+\alpha)\right)\right]^{1 /(1-\delta)}$

where $\mathrm{A}$ is the intercept of the demand curve, $\alpha$ is the price elasticity, and $\delta$ is the income elasticity. To consider quality change in its most straightforward setting, I assume that the price $\mathrm{p}_{\mathrm{n}}$ remains constant across the two periods but that $\mathrm{A}$ increases due to quality improvement so that the demand curve shifts outward. ${ }^{68}$ The compensating variation is calculated from equation (4.1) where y is income:

$$
C V=\left\{\frac{(1-\delta)}{(1+\alpha)} y^{-\delta}\left[p_{n}^{2} x_{n}^{2}-p_{n}^{1} x_{n}^{1}\right]+y^{(1-\delta)}\right\}^{1 /(1-\delta)}-y^{1}
$$

\footnotetext{
${ }^{68}$ Thus, the coefficient A captures the attributes of the product which may be changed by the manufacturer or may change due to factors such as network effects, e.g. for cellular telephones. The combined effect of both a shift of the demand curve and a price change can be estimated in a straightforward manner using this approach. Of course, the econometric estimation must be able to separate out a shift of the demand curve from movement along a demand curve, which is one of the oldest problems in econometrics.
} 
If a greater quantity is bought at the same price, consumer welfare typically increases. ${ }^{69}$ I applied this approach to calculate the increase in consumer welfare from improved quality of cellular telephone networks in Hausman (1999).

${ }^{69}$ The compensated demand curves could intersect, which could lead to a decrease in consumer welfare. However, this outcome is unlikely to occur. 


\section{$\underline{\text { References }}$}

Abraham, K., J. Greenlees, and B. Moulton (1998), "Working to Improve the Consumer Price Index", Journal of Economic Perspectives, 12.

Berndt, E.R. Z. Griliches, and N.J. Rapport (1995), "Econometric Estimates of Price Indexes for Personal Computers in the 1990s, Journal of Econometrics, 68, 243-268.

Berry S., J. Levinson, and A. Pakes (1995), "Automobile Prices in Market Equilibrium," Econometrica, 63, 841-890.

Bils M. and P Klenow, "Quantifying Quality Growth", American Economic Review, 91, 1006-1030.

Boskin, M. et. al. (1996), "Toward a More Accurate Measure of the Cost of Living," Final Report to the Senate Finance Committee.

Bowley, A.L. (1899), “Wages, Nominal and Real," in R.H. Palgrave, ed., Dictionary of Political Economy, London: Macmillan, 640-651.

Bresnahan, T., "Comment," ed. T. Bresnahan and R. Gordon, The Economics of New Goods, University of Chicago Press, 238-241.

Costa, D.L. (2001), "Estimating Real Income in the US from 1888 to 1994: Correcting CPI Bias Using Engel Curves,” Journal of Political Economy, 109, 1288-1310.

Deaton A. and J. Muellbauer (1980), Economics and Consumer Behavior," Cambridge: Cambridge University Press.

Diewert, W.E. (1976), "Exact and Superlative Index Numbers," Journal of Econometrics, $4,114-145$.

Diewert W.E. (1980), “Aggregation Problems in the Measurement of Capital”, pp. 433528 in The Measurement of Capital, Dan Usher (ed.), Chicago: The University of Chicago Press

Diewert, W.E. (1993), "The Early History of Price Index Research," in W.E. Diewert and A.O. Nakamura, eds., Essays in Index Number theory, vol. I, Amsterdam: Elsevier.

Diewert, W.E. (1998), "Index Number Issues in the Consumer Price Index", Journal of Economic Perspectives 12, 47-58. 
Diewert, W.E. (2001), "Hedonic Regressions: A Consumer Theory Approach", forthcoming in Scanner Data and Price Indexes, R. Feenstra and M. Shapiro (eds.), Studies in Income and Wealth, Volume 61, Chicago: University of Chicago Press.

Fisher, I. (1922), The Making of Index Numbers, Boston: Houghton Mifflin.

Hamilton B.W. (2001), "Using Engel's Law to Estimate CPI Bias," American Economic Review, 91, 619-630.

Hausman J. (1979): "Individual Discount Rates and the Purchase and Utilization of Energy Using Durables," Bell Journal of Economics, 10.

Hausman, J. (1981), "Exact Consumer Surplus and Deadweight Loss," American Economic Review, 71, 662-676.

Hausman, J. (1996): "Valuation of New Goods Under Perfect and Imperfect Competition," ed. T. Bresnahan and R. Gordon, The Economics of New Goods, University of Chicago Press, 209-237.

Hausman, J. (1997a): "Valuation and the Effect of Regulation on New Services in Telecommunications," Brookings Papers on Economic Activity: Microeconomics, 1997

Hausman, J. (1997b): "The CPI Commission and New Goods," The American Economic Review, 87.

Hausman, J. (1999): "Cellular Telephone, New Products and the CPI," Journal of Business and Economics Statistics, 17, 188-194.

Hausman, J. (2002a): "Mobile Telephone," Forthcoming in M. Cave et. al, $\underline{\text { Handbook of }}$ Telecommunications Economics, Amsterdam: North Holland.

Hausman, J. (2002b): "Regulated Costs and Prices in Telecommunications," Forthcoming in G. Madden ed., International Handbook of Telecommunications," London: Elgar Publishing.

Hausman J. G. Leonard, and D. Zona (1994): "Competitive Analysis with Differentiated Products," Annales D'Economie et de Statistique, 34.

Hausman J. and G. Leonard (2002): “The Competitive Effects of a New Product Introduction: A Case Study", Journal of Industrial Economics, 50.

Hausman J. and W. Newey (1995): "Nonparametric Estimation of Exact Consumers Surplus and Deadweight Loss," Econometrica, 63.

Hicks, J.R. (1940), "The Valuation of the Social Income," Economic Journal, 42. 
Lowe, J. (1823), The Present State of England in Regard to Agriculture, Trade and Finance, $2 \mathrm{~d}$ ed., London: Longman, Hurst, Rees, Orme, and Brown

Konus, A. (1924), “The Problem of the True Index of the Cost of Living,” Econometrica, 7, 1939, 10-29.

Madrick, J., (2001), “Economic Scene”, New York Times, December 27, 2001, p. c2.

Marshall, A. (1887), "Remedies for Fluctuations of General Prices," in A.C. Pigou, ed., Memorials of Alfred Marshall, London: Macmillan, 1925.

Pakes, A. (2001), "Some Notes on Hedonic Price Indices, with an Application to PC's", paper presented at the NBER Productivity Program Meeting, March 16, Cambridge MA.

Petrin, A. (2002), "Quantifying the Benefits of New Products: The Case of the Minivan," Journal of Political Economy, 110, 705-729

Pollak, R. (1989), The Theory of the Cost-of-Living Index, Oxford University Press.

Rothbarth, E. (1941), "The Measurement of Changes in Real Income under conditions of Rationing," Review of Economic Studies, 100-107.

Schultze C. and C. Mackie, eds. (2002); At What Price?, Washington: Nation Academy of Sciences Press.

Shapiro, M. and D. Wilcox (1997), "Alternative Strategies for Aggregating Prices in the CPI,” Federal Reserve Bank of St. Louis Review, 79, 113-125.

Sidgwick, H. (1883), The Principles of Political Economy, London: Macmillan.

Silver, M.S. and Heravi S. (2001a), "Scanner Data and the Measurement of Inflation", The Economic Journal, 111, F384-F405

Silver, M.S. and Heravi S. (2001b), "Why the CPI matched models method may fail us: results from an hedonic and matched experiment using scanner data," Univ. Of Cardiff mimeo.

Spence, A.M. (1976), "Product Selection, Fixed Costs, and Monopolistic Competition," Review of Economic Studies, 43. 
Figure 1: New Product




Figure 2: Quality Change




Figure 3: Price Change

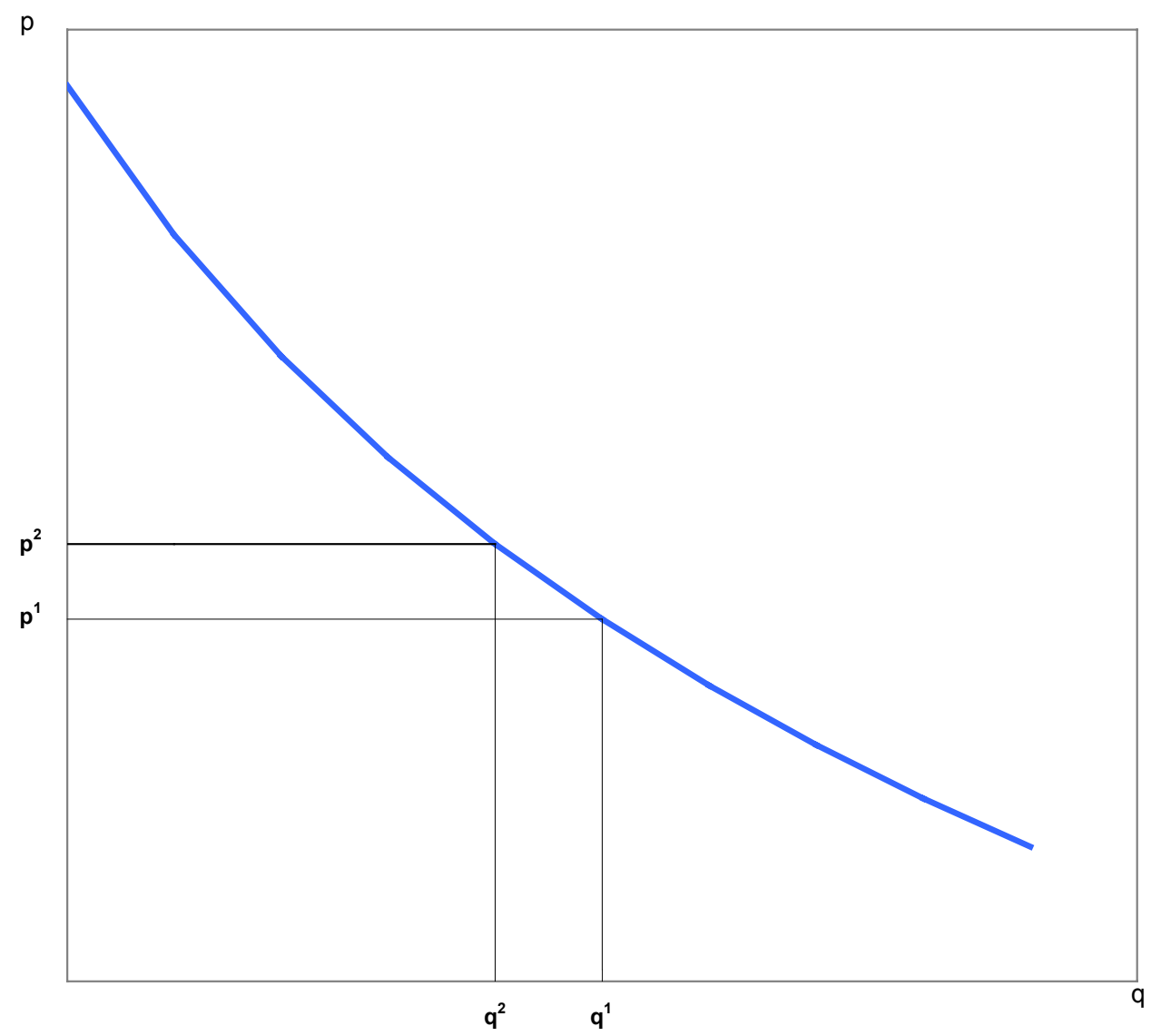

